\title{
SEJARAH PERKEMBANGAN TK AISYIAH BUSTANUL ATHFAL (TK ABA) DI KABUPATEN KATINGAN
}

\section{LILIK KHOLISOTIN}

\author{
Bekerja di Universitas Muhammadiyah Palangka Raya. \\ Jalan RTA Milono km I,5 Palangka Raya Kalimantan Tengah, \\ Telepon/Fax 05363238259, kode Pos 73 I I I \\ e-mail :lilik.kh1972@gmail.com
}

\begin{abstract}
ABSTRAK
Aisyiyah adalah suatu organisasi otonom Muhammadiyah yang didirikan bersamaan dengan peringatan isra' mi'raj Nabi Muhammad saw yang merupakan gerakan keputrian, dan bergerak dibidang keagamaan dan kemasyarakatan serta pemberdayaan perempuan dibidang kesehatan, ekonomi dan pendidikan. Pada usianya yang lebih dari seabad, 'Aisyiyah telah memberikan corak tersendiri dalam ranah sosial, pendidikan, kesehatan, dan keagamaan, yang selama ini menjadi titik tolak gerakannya. Perkembangan dan kemajuan TK ABA di seluruh pelosok Negeri, tentu berimbas di daerah-daerah lain di seluruh Indonesia, tak ketinggalan juga yang ada di Kasongan kabupaten Katingan yang merupakan bagian dari Kalimantan Tengah.

Tujuan dari penelitian ini adalah untuk mengetahui bagaimana sejarah perkembangan TK Aisyiah Bustanul Atfhfal (TK ABA) di Kasongan kabupaten Katingan. Metode penelitian yaitu metode Kualitatif dimana pada penelitian ini mendeskripsikan sejarah TK ABA di Kasongan melalui wawancara dengan pihak terkait, observasi di lingkungan TK ABA dan dokumentasi mengenai fasilitas, sarana dan prasarana. Luaran yang diharapkan pada penelitian ini adalah laporan komprehensif mengenai sejarah perkembangan TK ABA, publikasi ilmiah melalui jurnal Anterior.
\end{abstract}

Kata Kunci : Sejarah, TK ABA, Kabupaten Katingan

\section{ABSTRACT}

Aisyiyah is an autonomous Muhammadiyah organization that was established in conjunction with the commemoration of the Islamic missionary of the Prophet Muhammad who was a daughter movement, and engaged in religious and social affairs and empowerment of women in the fields of health, economics and education. At the age of more than a century, isy Aisyiyah has given its own features in the social, educational, health, and religious domains, which have been the starting point of her movement. The development and progress of TK ABA in all corners of the country, certainly impacted in other areas throughout Indonesia, not to mention also those in Kasongan, Katingan district which is part of Central Kalimantan.

The purpose of this study was to find out how the history of the development of TK Aisyiah Bustanul Atfhfal (TK $A B A)$ in Kasongan, Katingan district. The research method is a qualitative method in which this study describes the history of $T K A B A$ in Kasongan through interviews with related parties, observations in the TK ABA envronment and documentation of acilities, facilities and infrastructure. Expected output in this study is a comprehensive report on the history of the development of TK ABA, scientific publications through Anterior journals.

Keywords: History, TK ABA, Katingan Regency 


\section{Pendahuluan}

Berdirinya Aisyiyah tidak lepas dari peran Muhammadiyah dalam memberdayakan perempuan pada masa itu, dimana KH.Ahmad Dahlan adalah perintis yang bermula dari perkumpulan Sopo Tresno (artinya: siapa suka, siapa suka) yang merupakan kelompok pengajian yang terdiri dari anggotaanggotanya saat itu adalah perempuan-perempuan muda yang terdidik, berusia sekitar 15 tahun yaitu Aisyah (Hilal), Busyro Isom, Zahro Muchzin, Wadi'ah Nuh, Dalalah Hisjam, dan Badilah Zuber. Setelah Sopo Tresno tumbuh menjadi perkumpulan yang semakin matang, maka pada tanggal 27 Rajab $1335 \mathrm{H}$, bertepatan dengan 19 Mei 1917 M mendeklarasikan diri dengan nama Aisyiyah.

Kini 'Aisyiyah sebagaimana halnya Muhammadiyah terus mengembangkan dan memperluas struktur organisasi dan berbagai jenis amal usaha yang menyebar di seluruh penjuru tanah air. Gerakan kegiatan tabligh dan berbagai pembinaan keagamaan dan pengembangan amal usaha dibidang pendidikan dari tingkat dasar hingga perguruan Tinggi, bahkan TK ABA adalah ikon dalam gerakannya. Amal usaha dibidang pendidikan saat ini adalah mencapai 5.722 TK ABA yang tersebar di seluruh Indonesia.

Pertumbuhan dan perkembangan TK 'Aisyiyah Bustanul Athfal saat ini, tentu melalui sejarah perjalanan panjang baik di tingkat Pusat, Wilayah, Daerah, Cabang dan Ranting. Terlebih lagi akar rumpun perkembangannya justru terletak pada cabang dan rantingnya.

Berdasarkan informasi awal yang diperoleh peneliti melalui telpon seluler dengan Ketua 'Aisyiyah Periode 2016-202I bahwa di kabupaten Katingan memiliki 5 TK ABA yang terdiri I TK ABA yang terletak di Kasongan, 2 TK ABA yang ada di
Tumbang samba, I TK ABA di Dahian tunggal dan I TK ABA yang berada di Desa Palingkae. Keberadaan TK ABA tersebut tidak lepas dari peran 'Aisyiyah Kasongan kabupaten Katingan yang memiliki sejarah dalam pendiriannya.

Berdirinya Muhammadiyah di Kabupaten Kasongan serta periodesasi kepemimpinan yang ada di 'Aisyiyah dan Muhammadiyah tentu membawa perubahan pada amal usaha yaitu TK ABA Kasongan itu sendiri. Dari satu pemimpin ke pemimpin yang lain, adakah perkembangan TK ABA yang berada di Katingan tersebut? Jika dikaji sejarahnya tentu kita akan menengok ke belakang, bagaimana keberadaan awal dari TK ABA.

\section{Deskripsi Teoritik}

\section{A. Sejarah Berdirinya Organisasi ‘Aisyiyah}

Secara terminologi/istilah, 'Aisyiyah adalah suatau organisasi wanita dalam muhammadiyah yang mempunyai maksud dan tujuan sebagaimana maksud dan tujuan muhammadiyah. Aisyiyah didirikan pada tanggal 27 Rajab $1335 \mathrm{H}$, bertepatan pada 19 Mei 1917 M oleh K.H. Ahmad Dahlan yang di ketuai oleh istrinya Nyai Walidah (Profil Muhammadiyah, 2000)

Sebagai pendiri Muhammadiyah, Kyai Haji A.Dahlan sangat memperhatikan pembinaan terhadap wanita. Anak-anak perempuan yang potensial dibina dan dididik menjadi pemimpin, serta dipersiapkan untuk menjadi pengurus dalam organisasi wanita Muhammadiyah. Mereka yang dididik Kiyai Dahlan Diantaranya Siti Bariyah, Siti Dawimah, Siti Dalalah, SitiBusyro (putri beliau sendiri), Siti Dawingah, dan Siti Badilah Zuber.

Sejak usia 15 tahun anak-anak perempuan sudah diajak memikirkan soal-soal kemasyarakatan. Sebelum Aisyiyah secara kongkret terbentuk, sifat gerakan $\mathrm{P}$ embinaan wanita itu baru secara 
berkelompok belum merupakan organisasi. Oleh Kyai H. A. Dahlan dan Nyai Ahmad Dahlan kelompok tersebut dibimbing dan dibekali agama melalui pengajian.

Dalam perkembangannya, kelompok pengajian wanita itu diberi nama Sopo Tresna. Sopo Tresna belum merupakan organisasi, hanya suatu gerakan pengajian saja. Berkaitan dengan nama, $\mathrm{KH}$ Mokhtar mengadakan pertemuan dengan K. H. A. Dahlan dan pengurus Muhammadiyah lainnya. Dalam pertemuan itu diusulkan nama Fatimah, untuk organisasi perkumpulan kaum wanita Muhammadiyah itu, tetapi nama itu tidak diterima dalam forum rapat. Sementara Haji Fakhrudin kemudian mengusulkan nama'Aisyiyah, kemudian forum rapat menyepakati nama “Aisyiyah”. Nama 'Aisyiyah dipandang lebih tepat bagi gerakan wanita ini karena didasari pertimbangan bahwa perjuangan wanita yang akan digulirkan ini diharapkan dapat meniru perjuangan Aisyah r.a, isteri Nabi Muhammad SAW, yang selalu membantu Rasulullah dalam berdakwah.

\section{B. Sejarah perkembangan TK 'Aisyiyah}

\section{Hakikat Sejarah}

Meninjau hakikat sejarah, istilah sejarah secara etimologi berasal dari bahasa Arab yaitu "syajaratun" yang artinya "pohon" atau "asal-usul” yang kemudian seiring waktu berkembang dan diserapke dalam bahasa melayu "syajarah" yang akhirnya menjadi kata “sejarah" dalam bahasa Indonesia. Sedangkan sejarah dalam bahasa Inggris disebut "history" yang berasal dari bahasa Yunani yaitu "historia" yang berarti inquri, wawancara, interogasi dari seorang saksi mata dan juga laporan mengenai tindakan-tindakan (Sjamsudin, 2012: 13).
Sedangkan sejarah dalam pemaknaan terminologi dimaknai sebagai suatu ilmu yang mempelajari kejadian atau peristiwa masa lampau yang dikaitkan dengan aktivitas manusia yang berakibat pada munculnya perubahan pada peradaban umat manusia. Perubahan tersebut dapat berupa perkembangan, pertumbuhan, kemunduran dan kehancuran. Beberap ahli memberikan pandangan mereka tentang makna dari sejarah diantaranya:

a. Herodotus (484-425), mengatakan bahwa sejarah merupakan suatu kajian untuk menceritakan seluk beluk jatuh bangunnya seorang tokoh, masyarakat, ataupun peradaban (Hapsari, 2013: 7).

b. Muhammad Yamin, mendefinisikan sejarah sebagai ilmu pengetahuan yang disusun atas hasil penyeldidikan dari beberapa peristiwa yang dapat di buktikan (Tamburaka, 20I2: II).

c. Kuntowijoyo mengatakan sejarah yaitu rekontruksi masa lalu tentang apa yang dipikirkan, dikatakan, dikerjakan, dirasakan, dan didiami manusia.

Berdasarkan pendapat para ahli tersebut dipahami bahwa sejara adalah suatu peristiwa masa lalu yang dialami oleh manusia, dimana didalamnyaterdapat dimensi waktu dan tempat terjadinya suatu peristiwa. Sejarah juga tidak hanya berarti peristiwa yang terjadi pada masa lampau. Sejarah juga berarti kajian atau penelitian yang sistematis dari peristiwaitu, dengan kata lain sejarah sebagai ilmu. Dengan defenisi diatas dapat kita rumuskan bahwa, sejarah adalah ilmu pengetahuan yang mempelajari berbagai peristiwa atau kejadian penting dalam kehidupan umat manusia pada masa lampau.

\section{Pengertian Taman Kanak-kanak}


Merujuk kepada istilah bahasa Inggris, Kindergarten adalah istilah yang diberikan oleh Frobel-seorang tokoh pendidikan Jermanuntuk pendidikan pada anak yang dilakukan di luar rumah. Kindergarten di Indonesia dikenal dengan sebutan "Taman Kanak-kanak”. Hari ini kita, tidak asing lagi dengan istilah Taman Kanak-kanak, hampir semua lapisan masyarakat termasuk para orang tua dan praktisi maupun akademisi dibidang pendidikan ketika mendengar istilah ini.

Taman Kanak-kanak saat ini dapat disebut dengan sekolah, sama halnya dengan pendidikanpendidikan di tingkatan yang lebih tinggi. Akan tetapi, terdapat sedikit perbedaan pada Taman Kanak-kanak dengan jenjang pendidikan lainnya. Perbedaan itu mungkin tidak terlalu besar, tetapi sangat berpengaruh dalam proses pembelajarannya. Letak perbedaan tersebut adalah pada istilahnya yaitu "Taman", dengan istilah tersebut sudah terlihat perbedaannya bahwa di ruang ini tidak mengedepankan hasil prestasi akademik anak, melainkan yang lebih diutamakan adalah kesenangan dan kenyamanan anak selama berada di ruang tersebut. Istilah "Taman" itu sendiri dapat menggambarkan bahwa Taman Kanak-kanak merupakan taman yang nyaman dan menyenangkan bagi anak (Slamet Suyanto, 2005: 23). Tidak ada tuntutan bagi anak untuk mendapatkan ranking atau nilai akademik yang bagus, tetapi lebih memperhatikan pada proses anak dalam melewati tahap-tahap perkembangannya secara optimal tanpa tekanan yang berarti.

Pendidikan ditingkat taman kanak-kanak merupakan salah satu bentuk pendidikan anak usia dini, yaitu anak yang berumur $0-6$ tahun. Menurut Undang- Undang Nomor 20 Tahun
2003 Tentang Sistem Pendidikan Nasional Pasal I angka 14 dalam PENDIKNAS (2010: I) menyebutkan bahwa pendidikan anak usia dini merupakan upaya pembinaan yang ditunjukkan kepada anak sejak lahir hingga usia enam tahun yang dilakukan dengan pemberian stimulus pendidikan agar membantu perkembangan, pertumbuhan baik jasmani maupun rohani sehingga anak memiliki kesiapan memasuki pendidikan yang lebih lanjut.

Hal senada diungkapkan oleh Suyadi (2010: 18) dimana Taman Kanak-kanak dimaknai sebagai satu bentuk Satuan Pendidikan Anak Usia Dini pada jalur formal yang diselenggarakan bagi anak usia 4-6 tahun. Kemudian, kriteria tersebut dibagi menjadi dua kelompok yaitu anak usia 4-5 tahun masuk kelompok A (kecil) dan usia 5-6 tahun masuk kelompok B (besar). Pembelajarandi Taman Kanak-kanak (TK) dilaksanakan minimal lima hari dalam seminggu dengan jam layanan minimal 2,5 jam per harinya.

Sebagai wujud apresiasi dari beberapa pendapat di atas, saat ini pemerintahan juga turun memperhatikan perkembangan Taman Kanakkanak. Terbukti dengan adanya beberapa peraturan yang membahas detail tentang Taman Kanak-kanak. Salah satunya adalah pada Norma, Standar, Prosedur, dan Kriteria (NSPK) Petunjuk Pelaksanaan Program Taman Kanak-kanak Tahun 2013 menyatakan bahwa Taman Kanak-kanak adalah salah satu bentuk satuan pendidikan anak usia dini pada jalur formal yang menyelenggarakan program pendidika anak usia empat sampai enam tahun.

Berdasarkan beberapa pendapat tersebut, dapat diketahui bahwa Taman Kanak-kanak merupakan suatu lembaga pendidikan yang 
dipersiapkan khusus untuk anak-anak. Proses pembelajaran yang dilakukan di dalam Taman Kanak- kanak tidak menuntut produk atau output yang baik secara akademik, melainkan lebih memperhatikan proses anak dalam melewati tahapan perkembangannya.Selain itu, pembelajaran di Taman Kanak-kanak sebaiknya direncanakan dan dilakukan dengan tujuan untuk mengembangkan segala aspek perkembangan anak.

\section{Sejarah perkembangan TK 'Aisyiyah}

Dalam kamus besar bahasa Indonesia perkembangan adalah asal kata berkembang yaitu serangkaian gerak indah permainan pencak yang merupakan ekspansi kelenturan dan ketrampilan yang berguna untuk efektivitas serangan, tangkisan, elakan, tangkapan dan sebagainya. Sedang yang dimaksud sejarah perkembangan di sini adalah suatu proses perubahan yang berkesinambngan baik dalam bentuk jumlah, ukuran, volume maupun perubahan yang disebabkan oleh unsur-unsur yang lain.

\section{Identitas/ Profil Aisyiah}

Berdirinya 'Aisyiyah di Daerah Kabupaten Katingan tidak lepas dari sejarah berdirinya Muhammadiyah. 'Aisyiyah berdiri dengan diawali keberadaan Muhammadiyah terlebih dahulu. Masyarakat muslim di Kalimantan Tengah pertama kali mengenal Muhammadiyah hampir bersamaan caranya dengan sejarah masuknya

\section{d. Misi}

Misi 'Aisyiyah diwujudkan dalam bentuk amal usaha, program, dan kegiatan, meliputi:

$$
\begin{array}{lr}
\text { I) } & \text { keyakinan, } \\
\text { memperdalam dan memperluas } & \text { meningkatkan }
\end{array}
$$

Islam ke Indonesia, yaitu dibawa oleh para saudagar.

Tujuan didirikanya Aisyiyah di Kabupaten

Katingan antara lain:

a. Membimbing dan menyadarkan perempuan dalam beragama dan berorganisasi

b. Menghimpun perempuan-perempuan Muhammadiyah untuk turut serta menyalurkan dan menggembirakan amalanamalanya.

\section{Visi-misi}

\section{Adapun yang menjadi visi misi TK}

\section{'Aisyiyah}

a. Identitas

Aisyiyah adalah organisasi perempuan Persyarikatan Muhammadiyah, merupakan gerakan Islam, dakwah amar makruf nahi munkar dan tajdid yang berasas Islam serta bersumber kepada Al-Qur'an dan AsSunnah.

b. Visi Ideal

Tegaknya agama Islam dan terwujudnya masyarakat Islam yang sebenar-benarnya.

\section{c. Visi Pengembangan}

Tercapainya usaha-usaha 'Aisyiyah yang mengarah pada penguatan dan pengembangan dakwah amar ma'ruf nahi munkar secara lebih berkualitas menuju masyarakat madani.

$$
\text { pengamalan serta }
$$
menyebarluaskan ajaran Islam dalam segala aspek kehidupan.

2) Meningkatkan harkat dan martabat kaum perempuan sesuai dengan ajaran Islam. 
3) Meningkatkan kualitas dan kuantitas pengkajian terhadap ajaran Islam.

4) Memperteguh iman, memperkuat dan menggembirakan ibadah, serta mempertinggi akhlak.

5) Meningkatkan semangat ibadah, jihad, zakat, infaq, shodaqoh, wakaf, hibah, membangun dan memelihara tempat ibadah serta amal usaha yang lain.

6) Membina Angkatan Muda Muhammadiyah Puteri untuk menjadi pelopor, pelangsung, dan penyempurna gerakan 'Aisyiyah

7) Meningkatkan pendidikan, mengembangkan kebudayaan, memperluas ilmu pengetahuan dan teknologi, serta menggairahkan penelitian.

8) Memajukan perekonomian dan kewirausahaan ke arah perbaikan hidup yang berkualitas.

9) Meningkatkan dan mengembangkan kegiatan dalam bidang-bidang sosial, kesejahteraan masyarakat, kesehatan, dan lingkungan hidup.

10) Meningkatkan dan mengupayakan penegakan hukum, keadilan dan penulis sepenuhnya mengikuti metode sejarah yang terdiri atas empat langkah pokok, yaitu: (I) heuristik atau pengumpulan sumbersumber sejarah yang berisi data-data sejarah, (2) kritik atau seleksi atas sumber-sumber sejarah, (3) interpretasi atau penafsiran terhadap faktafakta sejarah sebagai hasil dari langkah kritik, kebenaran, serta memupuk semangat kesatuan dan persatuan bangsa.

II) Meningkatkan komunikasi, ukhuwah, kerjasama di berbagai bidang dan kalangan masyarakat baik dalam dan luar negeri.

12) Usaha-usaha lain yang sesuai dengan maksud dan tujuan organisasi

13) Membimbing dan mengarahkan anak agar mandiri dalam kebutuhan dan permasalahan sendiri.

\section{Tujuan :}

Membentuk anak yang berkarakter islami, berkualitas, yaitu anak yang tumbuh dan berkembang sesuai dengan perkembangan dan memiliki kesiapan dalam memasuki pendidikan dasar.

\section{METODE PENELITIAN}

Penelitian ini merupakan penelitian sejarah yang menggunakan metode sejarah. Metode sejarah, mengutip Gottschalk (1983: 32), dapat dipahami sebagai proses untuk menguji dan menganalisis secara kritis rekaman dan peninggalan masa lalu, yang identik dengan sumber sejarah. Dalam kajian penelitian ini, dan (4) historiografi atau penulisan karya sejarah. Penelitian ini juga menggunakan metode Kualitatif dimana penelitian ini akan mendeskripsikan sejarah TK ABA di Kasongan melalui wawancara dengan pihak terkait, observasi di lingkungan TK ABA dan 
dokumentasi mengenai fasilitas, sarana dan prasarana.

\section{PEMBAHASAN DAN HASIL PENELITIAN}

\section{A. Profil TK ABA Kasongan}

\section{Visi}

Menjadikan generasi penerus menjadi seorang pemimpin yang bijaksana dan bertanggung jawab, jujur dalam tindak dan ucapan serta menghargai dan menghormati sesamanya serta beriman dan bertakwa kepada Tuhan Yang Maha Esa.

\section{Misi}

Untuk mencapai visi, misi dan tujuan diatas:

a. Membentuk perilaku anak melalui pola hidup yang sederhana secara terus menerus dalam proses belajar mengajar di Taman Kanakkanak sesuai dengan tingkat perkembangan dalam usia sehingga menjadi kebiasaan hidup sehari-hari.

b. Mengembangkan kemampuan dasar anak didik untuk memperoleh daya cipta,bahasa daya pikir, keterampilan dan jasmani sesuai dengan tingkat perkembangan intelektual anak.

3. Maksud dan Tujuan berdirinya TK Aisyiyah

Adapun maksud dan tujuan Pendirian Taman

Kanak-kanak

"Aisyiyah Bustanul

Atfhal"adalah sebagai berikut sebagai berikut.

b) Kegiatan spontan

c) Kegiatan dengan teladan contoh

d) Kegiatan dilakukan dengan perencanaan terprogram bersama guru a. Membantu pemerintah untuk memperluas jangkauan daya tampung sekolah (TK) sehingga dapat menjangkau anak-anak yang berada di sekitar lokasi tanpa memandang status sosial, budaya serta suku agama.

b. Membangun manusia yang beriman dan bertakwa terhadap Tuhan yang Maha Esa dan berbudi luhur, memiliki pengetahuan dan keterampilan sejak usia dini, sehat jasmani dan rohani, berkepribadian mantap, mandiri dan bertanggung jawab.

c. Membuka lapangan kerja bagi tenaga lulusan guru yang tidak bisa diangkat oleh Pemerintah, maka pihak swasta dapat memanfaatkan ilmu yang diperoleh dengan imbalan yang pantas baginya

\section{Kegiatan Belajar}

Untuk mencapai visi, misi dan tujuan diatas, maka program belajar di Yayasan Aisyiyah terdiri dari:

a. Program aktivitas belajar mengajar

I) Isi program kegiatan ini membuat kegiatan belajar yang dipandu secara utuh mencakup:

2) Program pembentukan perilaku melalui kebiasaan hidup sehari-hari.

3) Program pembangunan kemampuan dasar yang dilaksanakan dalam
a) Kegiatan rutin

4) Tema kegiatan ini merupakan wadah untuk mengembangkan kemampuan anak yaitu dibuat dalam pokok-pokok diambil dari yang terdekat sampai kepada halhal yang terjauh. 
5) Relasi/ hubungan antar kemampuan dasar, tema dan pembentukan dasar perilaku melalui kehidupan sehari-hari.

b. Pelaksanaan kegiatan belajar mengajar

c. Perencanaan kegiatan sehari-hari tterdiri dari:

I) Perencanaan tahunan dan semester

$\begin{array}{ll}\text { 2) Perencanaan mingguan } \\ \text { 3) } & \text { Perencanaan kegiatan } \\ \text { harian } & \end{array}$

d. Pengelola kelas, memperhatikan halhal sebagai berikut:

I) Hari-hari pertama masuk sekolah

2) Metode belajar mengajar

3) Pengorganisasian anak

4) Pengorganisasian ruang kelas

e. Evaluasi dilakukan terhadap:

I) Penilaian terhadap belajar mengajar

2) Penilaian perkembangan anak

Adapun waktu dalam pelaksanaan KBM dimulai setiap hari senin-sabtu pada pukul.07.00- 9.30 wib

Aisyiyah ini adalah membantu pemerintah untuk memperluas jangkauan daya tampung sekolah sehingga bisa menjangkau anak-anak yang berada di sekitar lokasi tanpa memanadang status sosial, budaya serta suku agama, membangun manusia yang
Hasil temuan penelti di lapangan, bahwa berdiri TK ABA Katingan adalah sejak Tahun 1969, mengingat saat itu Katingan masih belum pemekaran, masih menginduk kepada Sampit Kota Waringin Timur, sehingga segala dokumen waktu itu belum terarsipkan. Beruntung ada seorang ibu yang menulis di sebuah catatan Sejarah lahirnya TK Aisyiyah, sehingga bukti sejarah baik 'Aisyiyah maupun TK ABA masih dapat dilacak.

Sejak berdirinya pimpinan daerah Aisyiyah di Kasongan. Keadaan Aisyiyah Kasongan semakin membaik dan semakin nyata dan tampak kehadirannya di tengah masyarakat. Aisyiyah Kasongan menjadi hidup kembali. Berbagai upaya dilakukan untuk mencari dana organisasi, dengan demikian banyak kegiatan yang bisa dilaksanakan. Anggota Aisyiyah Kasongan pun semakin bertambah. Mudah-mudahan untuk seterusnya Aisyiyah Kasongan akan selalu berkembang pesat seperti daerah-daerah lain. (catatan sejarah dan perkembangan TK ABA).

Dari hasil wawancara peneliti di lapangan berdirinya TK ABA Katingan ini memliki beberapa periode yaitu, Periode I sampai dengan Periode IV. Dan dengan riwayat kepala sekolah TK ABA Katingan yang sudah berganti selama sepuluh periode dari tahun 1969 sampai dengan sekarang. Ini menandakan bahwa setiap tahunnya kondisi TK ABA Katingan semakin membaik baik dar tingkat pembanggunannya, guru pengajarnya dan bertambahnya anak didik atau murid-murid TK ABA yang ada di Katingan. Tujuan dari berdirinya TK

beriman dan bertakwa terhadap Tuhan yang Maha Esa dan berbudi luhur serta membuka lapangan kerja bagi tenaga lulusan guru yang tidak bisa diangkat oleh pemerintah. 
Dari hasil wawancara dan dokumen yang diperoleh, perkembangan TK ABA Kasongan mengalami peningkatan yang cukup, baik dari kuantitas Guru maupun siswa nya.

\section{BAB IV}

\section{HASIL DAN PEMBAHASAN}

\section{Kelahiran dan Perkembangan Aisyiyah}

\section{Kasongan}

I. Periode I

$$
\text { Organisasi muhammadiyah yang }
$$
didirikan oleh $\mathrm{KH}$. A Dahlan pada tanggal 8 Dzulhijjah $1330 \quad \mathrm{H}$ atau tanggal 18 November $1912 M$ dengan kegiatan dakwahnya, telah masuk ke daerah aliran sungai Katingan yaitu Mendawai sejak tahun 1929. Dimulai dari hulu Katingan yaitu dari Tumbang Sanamang terus ke Muara sampai ke Pagatan.

Warga pertama sebagai warga Muhammadiyah di Tumbang Sanamang adalah keluarga Abdul Manaf dan H. Jamain. Di Tumbang Samba keluarga H. Durasid, Matseh, Abdurahman dan Maryamah. Selanjutnya di Kasongan keluarga Litang, Dullah, Rapet, Akhmad dan Atak, dan lainlain.

Seiring dengan berkembangnya organisasi Muhammadiyah di Katingan khususnya Kasongan, pada masa itu dengan sendirinya anak-anak dari warga

Pada tahun 1967, dengan kembalinya saudari Jimah Rappet setelah selesai kuliahnya di Palangkaraya. Jimah Rapet semasa kuliahnya memang aktif di NA. la mengumpulkan anak-anak usia 7 tahun
Muhammadiyah/Aisyiyah dibimbing dan dibina untuk mengamalkan ajaran Islam yang murni kembali pada Alquran dan Sunah Rasul Nabi Muhammad saw, dan memasukkan anak mereka ke sekolah Muhammadiyah. Karena pada zaman penjajahan Belanda waktu itu yang ada hanya sekolah Zending.

Pada tahun 1932 berdirilah sekolah Muhammadiyah di Tumbang Sanamang, Tumbang Samba, dan Kasongan dengan nama "Standart School Muhammadiyah". Para pendidik atau Ustadzahnya antara lain :

I. Iskandar Hasan dari Banjarmasin

2. Guru Rasidi dari Labiu

3. Guru Nabawi dari Yogyakarta

4. Guru Syarkawi dari Yogyakarta

Sekolah-sekolah Muhammadiyah itu kemudian telah melahirkan tokoh-tokoh masyarakat dan pejuang bangsa seperti Syaifuddin Dana (pejuang Kalteng), Arbain Sameng (pejuang Kalteng), Tarbani Dullah Hanafi dengan panggilan Tayang, Mas Amsyar Akhmad dan Dase Durasid yang sudah berulang kali duduk di DPR pusat dan juga pernah menjabat Pimpinan Wilayah Muhammadiyah Kalimantan Tengah. Jadi satu-satunya sekolah yang mampu menandingi sekolah Zending Kruten pada zaman penjajahan Belanda waktu itu adalah sekolah Muhammadiyah.

2. Periode II

keatas untuk belajar Alquran/ huruf Hijaiyah di rumah merekka. Hampir setiiap sore di rumahnya dilaksanakan sholat magrib bersama jamaah. Antara magrib dan isya ia mengarahkan anak-anak laki-laki dan 
perempuan yang usia belasan tahun (setingkat SD). Diadakannya Tanya jawab secara berekelompok, semacam cerdas cermat berkenaan dengan pelajaran di SD, baik tentang pelajaran umum maupun pelajaran agama. Di samping itu ibu-ibu diajak juga untuk kumpul-kumpul semacam pengajian yang diadakan satu kali seminggu dan diisi dengan ceramah.

Pengajian anak-anak dan ibu-ibu berjalan terus. Pada suatu hari ibu Jimah Rapet mengajak ibu $\mathrm{Hj}$. Sunarti Achmad tentang bagaimana seandainya mendirikan organisasi Aisyiyah di tempat kita di Kasongan, kita mulai lagi menghidupkan Aisyiyah kembali yang sudah puluhan tahun sejak zaman penjajahan jepang beku. Akhirnya Aisyiyah kembali hidup di Kasongan pada tahun 1968. Susunan pengurus Asiyiyah Kasongan pada waktu itu, periode tahun 1968-1970 yaitu.

$\begin{array}{ll}\text { Ketua } & \text { : Jimah Rapet } \\ \text { Wakil ketua } & \text { : Maslimah } \\ \text { Sekretaris } & \text { : Nati H. Usman } \\ \text { Bendahara } & \text { : Isnaniah } \\ \text { Anggota } & \text { : Ny Saeroh Dullah } \\ & \text { Ny Tabrani Dullah } \\ & \text { Ny Rohana Dullah }\end{array}$

Kemudian susunan pengurus tersebut diatas berganti lagi pada tahun 1970, dengan susunan pengurus sebagai berikut.

\section{Ketua : Jimah Yasan Hezas}

Sufyan Karim pada tanggal 4 Juli 1987 dan di sambut dengan surat keputusan Nomor I43/PPA/A/VIII/I 988 pada tanggal 3 Agustus 1988.

$\begin{array}{ll}\text { Wakil ketua } & \text { : Ny. Maslimah } \\ \text { Sekretaris I } & \text { : Sunarti Achmad } \\ \text { Sekretaris II } & \text { : Siti Rosiani } \\ \text { Anggota : Siti R Misni } \\ \text { Ny Rohana } \\ \text { Ny Siter }\end{array}$

3. Periode III

$$
\text { pada periode ketiga keadaan }
$$
Aisyiyah Kasongan cukuo membaik, anggotanya mulai bertambah. Pengajian dilaksanajan secara rutin yaitu setiap tanggal 10 dan 25 setiap bulan. Banyak kegiatan yang diadakan oleh Aisyiyah kasongan pada periode ini.

Pengurus Aisyiyah Kasongan pada periode ke III ini adalah

Ketua umum : Ny. Elmi Amsyar Achmad

Ketua I

: Ny. Jimah Yasan

Hezas

Ketua II

Ketua III

Sekretaris I

Sekretaris II

Litang

$\begin{array}{lc}\text { Bendahara I } & \text { : Duna } \\ \text { Bendahara II } & \text { : Hamisah } \\ \text { Anggota } & : \text { Saerah Dullah } \\ & \text { Niah Tabrani } \\ & \text { Rohana Dullah }\end{array}$

Pengurus diatas dilantik oleh pimpinan wilayah Kalimantan Tengah, ibu Rumiati Sejak tahun 1987 sampai tahun 2002 Aisyiyah cabang Kasongan tidak ada melaksanakan musyawarah cbang. Syukur Alhamdulillah, akhirnya pada tahun 2002 kader-kader baru Aisyiyah bermunculan dan 
musyawarah cabang Kasongan dapat dilaksanakan.

4. Periode IV

Musyawarah cabang III Aisyiyah Kasongan dilaksanakan saat masyarakat Katingan sedang dalam penantian, yakni pengesahan Katingan menjadi sebuah kabupaten. Musyawarah cabang III Aisyiyah Kasongan dilaksanakan pada tanggal 7 April 2002, yang kemudian menghasilkan beberapa program kerja.

Keadaan Aisyiyah Kasongan agak
membaik, meskipun kegiatan yang
dilaksanakan masih hanya terbatas pada
kegiatan rutin saja. Hal ini disebabkan karena
kurangnya dana organisasi dan juga sebagian dari anggota PCA Kasongan memiliki kesibukan masing-masing, sehingga waktu untuk memikirkan organisasi hampir tidak ada.

Sejak berdirinya pimpinan daerah Aisyiyah di Kasongan. Keadaan Aisyiyah Kasongan semakin membaik dan semakin nyata dan tampak kehadirannya di tengah masyarakat. Aisyiyah Kasongan menjadi hidup kembali. Berbagai upaya dilakukan untuk mencari dana organisasi, dengan demikian banyak kegiatan yang bisa dilaksanakan. Anggota Aisyiyah Kasongan Kasongan pun semakin bertambah. Mudahmudahan untuk seterusnya Aisyiyah Kasongan akan selalu berkembang pesat seperti daerah-daerah lain.

2. dan dorongan terhadap program-program kepala sekolah dan guru-guru untuk meningkatkan kemajuan TK ABA Kabupaten Kasongan

\section{KESIMPULAN}

Berdasarkan hasil penelitian dan pembahasan yang telah diuraikan maka peneliti ini dapat menyimpulkan bahwa, dari periode berdirinya TK ABA di Katingan yang awal mulanya bisa dikatakan baru merintis, namun hingga sekarang terdapat perkembangan yang cukup baik dari segi perkembangan gedung sekolah, tenaga pengajar serta jumlah siswa yang semakin bertambah.seperti yang telah dijelaskan maksud tujuan dari berdirinya TK ABA adalah membantu pemerintah untuk memperluas jangkauan daya tampung sekolah sehingga bisa menjangkau anak-anak yang berada di sekitar lokasi tanpa memanadang status sosial, budaya serta suku agama, membangun manusia yang beriman dan bertakwa terhadap Tuhan yang Maha Esa dan berbudi luhur serta membuka lapangan kerja bagi tenaga lulusan guru yang tidak bisa diangkat oleh pemerintah. Sehingga dari waktu ke waktu TK ABA yang sudah mulai dikenal oleh masyarakat sekitar dapat berkembang dengan baik pula.

\section{SARAN}

Beranjak dari kesimpulan diatas, ada beberapa hal yang dapat mejadikan saran yaitu sebagai berikut :

I. Untuk Pimpinan Daerah Aisyiyah Kabupaten Katingan untuk meningkatkan kegiatan guruguru TK ABA mulai dari persiapan pelaksanaan dan evaluasi pembelajaran di TK ABA. Senantiasa memberikan dukungan

3. Untuk tenaga pengajar atau guru-guru yang berada di lingkungan TK ABA agar selalu mengarsipkan dokumen penting agar menjadi momen sejarah yang tidak 
dilupakan. Dan lebih meningkatkan lagi proses belajar mengajar serta kurikulum disesuaikan dengan majelis pendidikan dasar dan menengah Aisyiyah.

\section{DAFTAR PUSTAKA}

Abdurrahman, Dudung. 1999. Metode Penelitian Sejarah. Jakarta: Logos Wacana.

2010. Sejarah Kauman Menguak Identitas Kampung Muhammadiyah. Yogyakarta: Sura Muhammadiyah.

Creswell, J. W. (2010). Research design: pendekatan kualitatif, kuantitatif, dan mixed. Yogjakarta: PT Pustaka Pelajar.

Gottschalk, Louis. 1983. Mengerti Sejarah, terjemahan Nugroho Notosusanto. Jakarta: UI Press.

Hadi, Sutrisno.2002. Metodologi Riset. Yogyakarta: Andi Ofset.

Hapsari, Ratna dan M. Adil. 2013. Sejarah Indonesia jilid I Untuk SMA/MA Kelas X. Jakarta: Erlangga.

Kartodirdjo, Sartono. 1982. Pemikiran dan Perkembangan Historiografi Indonesia Suatu Alternatif,. Jakarta: Gramedia.

Kartodirdjo, Sartono.1993. Pendekatan Ilmu Sosial dalam Metodologi Sejarah. Jakarta: Gramedia Pustaka Utama.

Koentjaraningrat, "Metode Wawancara," dalam Koentjaraningrat (ed.). 1994. Metodemetode Penelitian Masyarakat. Jakarta: Gramedia.

Kuntowijoyo. 1995. Pengantar Ilmu Sejarah. Yogyakarta: Bentang Budaya.

Suyadi. 2010. Psikologi Belajar Anak Usia Dini. Yogyakarta : Pedagogia.

Suyanto, Slamet. 2005. Pembelajaran untuk Anak TK. Jakarta: Depdiknas.
2003. Metodologi Sejarah. Yogyakarta: CV. Tiara Wacana.

Maarif, Ahmad Syafii. 1987. Islam dan Masalah Kenegaraan Studi tentang Percaturan dalam Konstituante. Jakarta: LP3ES.

Moleong, Lexy J.,200I. Metodologi Penelitian Kualitatif. Bandung: Remaja Rosdakarya.

Mu'arif dan Hajar Nur Setyowati. 201I. Srikandisrikandi 'Aisyiyah, (Yogyakarta: Suara Muhammadiyah.

Mulyana, Deddy (2012) Metodologi Peneltian Kualitatif. Bandung : Remaja Rosdakarya.

Pimpinan Pusat Aisyiyah (2007). Sejarah Pertumbuhan dan perkembangan Aisyiyah. Yogyakarta : PP. Aisyiyah.

Puar, Yusuf Abdullah. 1989. Perjuangan dan Pengabdian Muhammadiyah, Jakarta: Pustaka Antara.

Putra, Nusa dan Dwilestari, Ninin. 2012. Penelitian Kualitatif PAUD. Jakarta: PT. Raja Grafindo.

Sjamsudin, Helius. 2012. Metodologi Sejarah. Yogyakarta: Ombak.

Storey, William Kelleher. 20II. Menulis Sejarah Panduan untuk Mahasiswa. Alih bahasa Abdillah Halim. Yogyakarta: Pustaka Pelajar.

Sugiyono. 2011. Metode Penelitian Kuantitatif, Kualitatif dan R\&D. Bandung: Afabeta.

Sutopo, HB. 2006. Metode Penelitian Kualitatif. Surakarta: UNS Press.

Suwarno, 2014. "Aisyiyah: Pelopor Gerakan Pemberdayaan Perempuan di Indonesia," dalam Suswandari, dkk. Berbincang tentang Perempuan dan Pendidikan untuk Kesetaraan Gender. Jakarta: Pusat Pelayanan Terpadu Pemberdayaan Perempuan dan Anak [P2TP2A].

Tilaar, H.A.R. 20I2. Kalaedoskop Pendidikan Nasional. Jakarta: Kompas.

Tim Penyusun dan Penerbit Profil Muhammadiyah (2000) Profil Muhammadiyah, Yogyakarta : Pimpinan Pusat Muhammadiyah 


\section{Jurnal}

Ramdhani, M. T., Lastaria, L., \& Ariyadi, A. (2019). Pembelajaran Ekonomi dalam Islam pada Materi Mudharabah di Pondok Pesantren. Anterior Jurnal, 19(I), 32-40.

Norcahyono, N., \& Ariyadi, A. (2019). Pandangan Majlis Tarjih Muhammadiyah Kalimantan Tengah Tentang Tindakan Euthanasia Dalam Pendidikan Waris Islam. Tunas: Jurnal Pendidikan Guru Sekolah Dasar, 5(1), 50-61. 